\title{
Experiences of Anoxia: Do Reflex Anoxic Seizures Resemble Near-Death Experiences?
}

\author{
Susan Blackmore, Ph.D. \\ University of the West of England
}

ABSTRACT: The role of anoxia in near-death experiences (NDEs) has been hotly debated. Some argue that anoxia can induce NDEs; others that its effects are quite different. Children suffering from reflex anoxic seizures (RAS) have repeated brief cardiac arrests. A questionnaire about their experiences was sent to members of the British RAS Support Group; 112 questionnaires were completed and 7 children were interviewed. Most recalled nothing from their seizures, but $24 \%$ reported some experience. A few were comparable to NDEs, with tunnels, lights, and out-of-body experiences.

The possible role of cerebral anoxia in near-death experiences (NDEs) has been appreciated since the early days of near-death research (Moody, 1977; Osis and Haraldsson, 1977), and has been argued over ever since (Morse and Perry, 1990; Ring, 1980; Sabom, 1982). On the one hand it is clear that anoxia plays some role. The areas of the brain most closely associated with the organization of memory, such as the hippocampus and limbic system, are especially sensitive to anoxia, as is the temporal lobe, whose stimulation is known to give rise to memory flashbacks and to floating and out-ofbody sensations. On the other hand, many NDErs clearly are not suffering from cerebral anoxia at the time of their experience. There has been much argument over one case in which blood gases were

Susan Blackmore, Ph.D., is Senior Lecturer in Psychology at the University of the West of England. The author wishes to thank Trudie Lobban, coordinator of the Reflex Anoxic Seizures Support Group, for her invaluable help in sending out all the questionnaires and providing other useful information. Reprint requests should be addressed to Dr. Blackmore at the Department of Psychology, University of the West of England, Bristol BS16 2JP, United Kingdom. 
measured at the time of an NDE and found to be normal (Gliksman and Kellehear, 1990; Sabom, 1982), but in any case many NDEs are reported from people who were suffering extreme shock or fear, or who expected to die but were not suffering any immediate trauma. Clearly anoxia cannot be necessary for an NDE.

I have argued that anoxia is just one of many triggers that can induce cortical disinhibition, that is, a release of the normal inhibition leading to excessive random firing of neurons. Disinhibition is known to give rise to various kinds of hallucinations, depending on which parts of the brain are involved (Siegel, 1980). My suggestion is that all NDEs depend on cortical disinhibition, but that this can be caused by many different triggers, only one of which is anoxia (Blackmore, 1993).

Part of the argument rests on whether anoxia really does lead to NDE-like experiences. Some forms of anoxia, especially the slow anoxia due to high altitude or slow poisoning with some gases or with alcohol, produce states quite unlike NDEs. I have argued that it is the faster onset anoxia that produces the disinhibition necessary for an NDE-like experience to occur.

The most direct way to test this would be to induce anoxia experimentally and ask the subject what it feels like. This might be thought too dangerous and unethical, but in fact has been done. Lempert, Bauer, and Schmidt (1994) induced syncope, or fainting due to a sudden drop of blood pressure, in healthy adults by using hyperventilation and the Valsalva maneuver, increasing intrathoracic pressure by forced exhalation against the closed glottis. This produced hallucinations similar to NDEs. Also fighter pilots sometimes lose consciousness under very high gravitational or acceleration forces and are trained in centrifuges to cope with it. They sometimes report pleasant emotions and out-of-body experiences, but not full-blown NDEs (Whinnery, 1990, 1997). The present research concerns another situation in which anoxia occurs repeatedly, but is not life-threatening: reflex anoxic seizures (RAS).

RAS is most common in infants and young children, and is also sometimes called white breath holding, vagal attack, Stephenson's Syndrome, blue breath holding, or pallid infantile syncope. Children suffering from RAS are often misdiagnosed as epileptic, and sometimes given years of inappropriate and possibly damaging medication, although the condition is now being increasingly recognized (Appleton, 1993; Stephenson, 1978). 
A reflex anoxic seizure is caused by a brief cardiac arrest that results from excessive activation of the vagus nerve in response to a sudden shock, pain, or other surprise. RAS is most common in babies and toddlers, and more common in girls (Stephenson, 1980). In a typical episode, the child suffers a shock. A few seconds later he or she will stiffen, clench the jaw, possibly jerk once or twice, and often become deathly white. Their eyes roll up into the head and they may have urinary incontinence. They may be unconscious for anything from a minute or two to more than an hour. Sometimes the patient wakes briefly and then goes into an unnaturally deep sleep for two or three hours.

There is no danger in RAS attacks themselves, and the child invariably recovers in due course. The only recommended action is to put the patient into the recovery position and wait. However, the attacks are terrifying to watch and many parents and carers, quite naturally, think their child is dead or dying. Some have tried resuscitation, which can be dangerous. Management of the condition therefore mostly involves reassuring the parents and teaching them how to care for the child during an attack, rather than treating the child, although atropine is sometimes used and a few children have been fitted with pacemakers.

In the media, RAS is often associated with dying, in such headlines as "Mummy, I've died again" (Sunday Mirror, 24 April 1994) and "The children who 'die' over five times a week" (Observer, 2 May 1993), and descriptions of "the boy who has 'died' 300 times" (Grantham Journal, 26 November 1993). Newspapers have reported cases of children seeing a bright warm light, and having out-of-body experiences in which they can observe the events from above. However, it is not known whether such experiences are common in RAS sufferers, and this study aimed to find out.

\section{Method}

A questionnaire was distributed to all members of the British Reflex Anoxic Seizure Support Group. This is run by the mother of an RAS sufferer for the support of other families with RAS sufferers. The questionnaire was sent out to the approximately 400 members with their regular newsletter starting with the December 1993 issue. Unfortunately the precise number of questionnaires sent out is not known. I sent 200 to the organizer, and when she ran out she kindly 
made more copies and sent them out to all new members without keeping a precise record. Questionnaire collection ended in June 1995. Questions concerned the sufferer's age, age at first attack and at diagnosis, and a series of possible experiences thought to be relevant to anoxia.

Seven children, aged between 7 and 13 years, were interviewed at a conference of the RAS support group in October 1994. The youngest was interviewed with her mother; the others on their own, though their parents were at the conference. The questions followed the structure of the questionnaire and then I added open-ended questions about their experience of RAS attacks. Interviews were tape recorded and later transcribed.

\section{Results}

A total of 112 questionnaires were completed. A further 15 questionnaires were received well after the deadline and, though they could not be included in the analysis, comments from some of them have been included where appropriate.

Only three of the children were old enough to complete the questionnaire themselves; 93 percent were completed by the child's mother and 4 percent by his or her father. Fifty-seven percent were female. The mean age of the child's first attack was 16 months, though two reported very early first attacks, one "at birth," the other at a half hour after birth. The oldest reported first attack was at age 14. The frequency of attacks was highly variable, but many reported weekly or even daily attacks.

An open-ended question asked parents to describe in as much detail as they could anything that their child has told them about how he or she feels before, during, or after an attack. Thirty-three percent wrote nothing. Many said their child was too young to say anything. Most of the other comments concerned how the attacks appeared to the parents. Several noted that their child became very clingy and wanted to be cuddled for some time after an attack. Many slept for a long time afterwards, waking up having apparently forgotten all about it. Some noted that the child seemed to remember the cause of the attack, such as who bumped them or what surprised them, but not the attack itself. A few parents mentioned that the child looked terrified in the moments before passing out. Some felt sick. 
Two noted that their children suffered from sleep disturbances or night terrors after attacks.

Yes/no answers were requested concerning 12 possible experiences that have been reported in NDEs and other types of anoxia. The percentages answering "yes" are shown in Table 1. Most people (76 percent) did not report any of the experiences. Among the 26 (24 percent) who did report them, the number of experiences ranged from 1 to 11 .

When additional descriptions were given, the lights included a pink haze and blurred vision. A 7-year-old girl reported "spots of colours, red, blue, black and yellow, mostly black. Also patterns," and enclosed a drawing of the colored streaks. Sounds included a fuzzy noise, a crackly noise, echoes, and high-pitched screaming. A 25-year-old woman who had her first attack at age 14 said that she recalls nothing from the attacks but hearing her own terrified scream on waking, although her husband said she does not actually scream.

Only five respondents claimed to have felt as though they were leaving the body, and most of those did not elaborate. One mother replied for her 6-year-old daughter, but added that she herself also had RAS as a child. "I used to lie in bed asleep and feel as though

Table 1

Frequency of Reported Experiences During RAS $(\mathbf{n}=\mathbf{1 1 2})$

\begin{tabular}{lr}
\hline \multicolumn{1}{c}{ Experience } & $\begin{array}{c}\text { Number of Subjects } \\
\text { (percent) }\end{array}$ \\
\hline Flashes of light & $9(8.0 \%)$ \\
Smells or tastes & $10(8.9 \%)$ \\
Sounds & $9(8.0 \%)$ \\
Tunnels & $4(3.6 \%)$ \\
Other regular patterns & $9(8.0 \%)$ \\
Sensations of floating or flying & $5(4.5 \%)$ \\
Falling sensations & $5(4.5 \%)$ \\
Feeling as though leaving the body & $5(4.5 \%)$ \\
Distortions of the body image & $9(8.0 \%)$ \\
Visions of other places & $4(3.6 \%)$ \\
Meetings with real or imaginary people & $9(8.0 \%)$ \\
Memories of events from the past & $5(4.5 \%)$ \\
\hline
\end{tabular}


I'd left my body and floated to the ceiling. I'd then wake up startled to find myself still in the bed with no covers moved. This has always baffled me but it hasn't happened since I was approx 14 years old."

Although nine respondents reported meetings with people, few made any further comment. One said that an imaginary person visits. Another mentioned people from earlier in the child's life. However, there were no descriptions of beings of light, of angels, of deceased friends or pets, or of any of the beautiful and inspiring scenes reported in some childhood NDEs (Atwater, 1996; Morse and Perry, 1990).

The largest number of experiences, 11 , was reported by a 9 -year-old boy I will call Alan, who had his first attack at age 2 and subsequent attacks daily or weekly. He was initially diagnosed as epileptic, and had many years of inappropriate medication until he was finally diagnosed as having RAS and fitted with a pacemaker. Both his parents recalled having out-of-body experiences (OBEs) at school during illness or injury. His mother has had several OBEs and two NDEs since childhood, one during Alan's birth.

In discussion and correspondence with his mother, I learned that before an attack Alan feels dizzy with a throbbing headache, like being hit by a hammer. He then frequently goes into a dark tunnel and is hurtled towards a light. On one recent occasion he was simply walking from the bathroom when he found himself already in the tunnel with the light coming towards him. The tunnel is clearly very frightening and unpleasant and he dreads it, but the "white light is nice, like a Christmas light."

He also reported distortions of his own body image and of other people. For example, at the start of an attack "people around me go into the distance." On waking, the voices around him are much louder. He said, "When I come out of the horrid tunnel everyone is much bigger and louder; I feel smaller than when I went in.”

He reported hearing whistling sounds, seeing patterns like snakeskin, and seeing people from past periods in his life, adding: "They're on the other side of the wall." He also reported floating, and in response to the question "Has your child ever reported feeling as though they are leaving the body?" he responded "Definitely."

Alan's first OBE occurred when he fell down stairs at age 2. $\mathrm{He}$ recalled seeing himself lying on the floor at the bottom of the stairs and going into a convulsion. Later he described an OBE at school after a bump on the head: "I saw the children standing over me after I had one of my black-and-white dreams." His parents described his 
worst attack as the one that occurred while walking from the bathroom. He had no pulse for at least a minute and a half and was dark blue. Alan later reported that he had been watching them and his sister from above as they leaned over him.

On one occasion he had an attack during a blood test. This is confirmed by the electrocardiogram, which showed several seconds without a heartbeat at the time of the blood test. Alan later said that he watched the doctor put in the needle, and the nurse move his teddy bear: "I saw her lift my legs."

Alan has since been fitted with a pacemaker and is able to lead an active life and play sports. He said that his déjà vu experiences have become less frequent. In a way, he misses the OBEs, but does not miss the collapses, the dreaded tunnels, or the black-and-white dreams.

Seven children were interviewed informally at an RAS conference. A 7-year-old girl I will call Angela was interviewed with her mother. She told me that normally she experienced nothing during her "little sleeps": "You don't know anything for that minute, you're just lying there for that minute not doing anything, not moving, not breathing, not nothing. . . . Then I come like wake up and then I start again." Interestingly, she said that sometimes she did remember what it was like, and that it was nice, or "lucky," to remember. For example, on one occasion when she fell off the kitchen work surface, she told her mother it was nice at the time, and later explained it to me: "It's all quiet and silent and really funny. ... It stops you from being hurt." She added: "You're not hurt when you're having it at all . . . but you are when it stops having it."

I asked Angela whether she had ever seen a tunnel or any funny lights. She answered: "Well, no, not really. . . . That's what I've been told by Grandma when you die." We went on to discuss what dying might be like and she added: "But you can never know if that's exactly what actually happens when you really die, when you quite die, 'cause you don't know what's down the tunnel, unless they wrote a letter ... but unless the angels may have brought it."

Some children described the feeling of being aware of what was going on around them, but being unable to speak or communicate in any way. A 9-year-old girl told me: "When my Mummy and Daddy talk to me when I'm dead, I can hear them." One 13-year-old girl told me that everything begins by feeling "all echoey and far away," then during the attack itself, "Sometimes I can't hear anything and other times I can. And when I can't hear anything I get scared. And 
people have to hold my hand." When I asked her how they knew she was scared, she explained the communication system that she and her mother had developed. During attacks she can move only her fingers. So she moves one finger to show she is scared, another to show she is too cold, another for too hot, and a fourth to show she is about to wake up. She said that she can be "out" for anything from 2 minutes to $21 / 2$ hours. I asked: "When it's $21 / 2$ hours, does it seem like that long?" "Longer," she replied.

\section{Discussion}

The questionnaires and interviews provide a general picture of what it is like to have RAS. While many of the children were too young to describe their experiences, and even many older ones remember little or nothing, those few who do remember reported experiences much like those associated with other types of anoxia and with NDEs, that is, tunnels, lights, out-of-body experiences, distortions of body image and of sounds and other people. However, they do not report very positive emotions, meetings with beings of light, or the beautiful places and scenes which are so frequently reported in NDEs.

As far as I know, the account of Alan's experience of watching the doctor insert a needle and the nurse move his teddy bear is the only case of a child having an $\mathrm{OBE}$ during a monitored cardiac arrest. However, it cannot help resolve questions about the nature of that OBE. It is quite possible either that something actually did leave the body and observe the scene from above, or that the OBE was the brain's reconstruction of events from a bird's eye view, based on the sensations of the needle and the sounds of activity around.

I should say, however, that moving a teddy bear does not make a lot of noise. Indeed, Alan's mother said: “I don't recall the nurse making a sound, either when moving 'Big Ted' or assisting the doctor. She literally grabbed the bear and cast him aside. [He] slid across the polished floor and came to rest under the bed." But I wish we had an independent record of what happened and of Alan's description of events. Without these, this anecdote simply adds to the many others that imply out-of-body vision but do not provide reliable evidence for it.

My conversation with Angela about what happens when one dies added to my impression that many children have far deeper and 
more insightful thoughts about death than adults give them credit for.

These children's descriptions of being aware of what was going on around them, but being unable to speak or communicate in any way, are reminiscent not only of NDEs, in which people are often frustrated by trying in vain to communicate with doctors or nurses, but of OBEs occurring in many traditions and cultures (Blackmore, 1993). The same thing is also reported by pilots in rapid-acceleration training (Whinnery, 1990, 1997).

Transformations of personality and various other aftereffects of NDEs are often reported in the literature, but it was not appropriate to investigate these here. Not only the child's life but the whole family's life can be severely disrupted by having RAS, and therefore any effects of the experiences in themselves could not be separated from the psychosocial effects of the disease.

Within the limitations of this study, these results show that transient, non-life-threatening anoxia can sometimes induce NDE-like experiences, but these are not like typical NDEs in all respects. I hope these results will add to our understanding of the role of anoxia in NDEs.

\section{References}

Appleton, R. E. (1993). Reflex anoxic seizures. British Medical Journal, 307, 214-215. Atwater, P. M. H. (1996). Children and the near-death phenomenon: Another viewpoint. Journal of Near-Death Studies, 15, 5-16.

Blackmore, S. J. (1993). Dying to live: Near-death experiences. Buffalo, NY: Prometheus.

Gliksman, M. P. H., and Kellehear, A. (1990). Near-death experiences and the measurement of blood gases. Journal of Near-Death Studies, 9, 41-42.

Lempert, T., Bauer, M,. and Schmidt, D. (1994). Syncope and near-death experience. Lancet, 344, 829-830.

Moody, R. A. (1977). Reflections on life after life. St. Simon's Island, GA: Mockingbird Books.

Morse, M., and Perry, P. (1990) Closer to the light: Learning from the near-death experiences of children. New York, NY: Villard.

Osis, K, and Haraldsson, E. (1977). Deathbed observations by physicians and nurses: A cross-cultural survey. Journal of the American Society for Psychical Research, 71, 237-259.

Ring, K. (1980). Life at death: A scientific investigation of the near-death experience. New York, NY: Coward, McCann and Geoghegan.

Sabom, M. B. (1982). Recollections of death: A medical investigation. New York, NY: Harper and Row.

Siegel, R. K. (1980). The psychology of life after death. American Psychologist, 35, 911-931. 
Stephenson, J. B. P. (1978). Reflex anoxic seizures (white breath-holding): Non-epileptic vagal attacks. Archives of Disease of Childhood, 53, 193-200.

Stephenson, J. B. P. (1980). Reflex anoxic seizures and ocular compression. Developmental Medicine and Child Neurology, 22, 380-386.

Whinnery, J. E. (1990). Acceleration-induced loss of consciousness: A review of 500 episodes. Archives of Neurology, 47, 764-776.

Whinnery, J. E. (1997). Psychophysiologic correlates of unconsciousness and near-death experiences. Journal of Near-Death Studies, 15, 231-258. 